DEPARTMENT OF THE INTERIOR

UNITED STATES GEOLOGICAL SURVEY

\title{
BASINS DRAINED BY SINKHOLES IN KNOX COUNTY, TENNESSEE By
}

\section{Leonard D. Harris}

FOLIO OF KNOX “COUNTY, TENNESSEE

MAP I-767 G

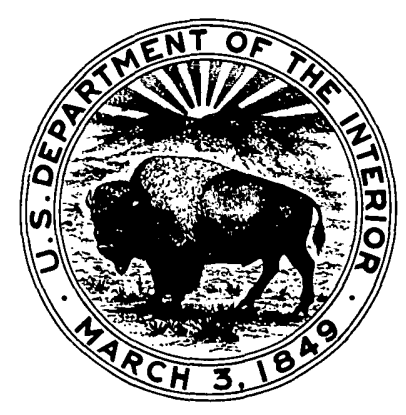

